\title{
The effect of tapering on a magnetocaloric regenerator bed
}

\author{
Dallolio, Stefano; Lei, Tian; Engelbrecht, Kurt; Bahl, Christian
}

Published in:

International Journal of Refrigeration

Link to article, DOI:

10.1016/j.jirefrig.2017.08.012

Publication date:

2017

Document Version

Peer reviewed version

Link back to DTU Orbit

Citation (APA):

Dallolio, S., Lei, T., Engelbrecht, K., \& Bahl, C. (2017). The effect of tapering on a magnetocaloric regenerator bed. International Journal of Refrigeration, 84, 300-308. https://doi.org/10.1016/j.ijrefrig.2017.08.012

\section{General rights}

Copyright and moral rights for the publications made accessible in the public portal are retained by the authors and/or other copyright owners and it is a condition of accessing publications that users recognise and abide by the legal requirements associated with these rights.

- Users may download and print one copy of any publication from the public portal for the purpose of private study or research.

- You may not further distribute the material or use it for any profit-making activity or commercial gain

- You may freely distribute the URL identifying the publication in the public portal

If you believe that this document breaches copyright please contact us providing details, and we will remove access to the work immediately and investigate your claim 


\section{Accepted Manuscript}

Title: The effect of tapering on a magnetocaloric regenerator bed

Author: S. Dall'Olio, T. Lei, K. Engelbrecht, C.R.H. Bahl

PII: $\quad$ S0140-7007(17)30331-6

DOI: $\quad$ http://dx.doi.org/doi: 10.1016/j.ijrefrig.2017.08.012

Reference: $\quad$ JIJR 3730

To appear in: International Journal of Refrigeration

Received date: 13-1-2017

Revised date: $\quad 9-8-2017$

Accepted date: $\quad 23-8-2017$

Please cite this article as: S. Dall'Olio, T. Lei, K. Engelbrecht, C.R.H. Bahl, The effect of tapering on a magnetocaloric regenerator bed, International Journal of Refrigeration (2017), http://dx.doi.org/doi: 10.1016/j.ijrefrig.2017.08.012.

This is a PDF file of an unedited manuscript that has been accepted for publication. As a service to our customers we are providing this early version of the manuscript. The manuscript will undergo copyediting, typesetting, and review of the resulting proof before it is published in its final form. Please note that during the production process errors may be discovered which could affect the content, and all legal disclaimers that apply to the journal pertain. 


\title{
THE EFFECT OF TAPERING ON A MAGNETOCALORIC REGENERATOR BED
}

\author{
S. Dall'Olio*, T. Lei , K. Engelbrecht, C. R. H. Bahl \\ Department of Energy Conversion and Storage - Technical University of Denmark, \\ Frederiksborgvej 399, DK - 4000 Roskilde, Denmark \\ *Corresponding author. E-mail: stefdal@dtu.dk (S. Dall’Olio) \\ Tel.: +45 93511167; fax: +45 46775858.
}

\section{Highlights:}

- The effect of tapering of an active magnetic regenerator bed is studied.

- Absolute performance increases as the absolute tapering angle decreases.

- The heating power decreases considerably moving from the optimal hot side temperature.

- Tapering exhibits better air-gap utilization compared to straight bed regenerator.

- By introducing tapering, the cost of the magnet of an AMR decreases.

\begin{abstract}
To design a high efficiency magnetocaloric heat pump for the residential sector, we focused on the improvement of the performance of the regenerator bed. In particular, placing the regenerators circumferentially on a plane, we decided to use tapered regenerators instead of the straight channel ones. Therefore, this paper investigates the effect of the tapering of the regenerators, which exhibit better air-gap utilization. Several simulations using a 1D AMR model were run to study the performance of the tapered regenerator, and the results were compared to the case of the straight regenerator bed. Moreover, the temperature span was held fixed at $25 \mathrm{~K}$, and the working temperature of the regenerator was shifted to study the sensitivity to the variation of the working conditions. This paper considers a 10-layer regenerator, with Curie temperature $\left(T_{\mathrm{C}}\right)$ spacing of $2.5 \mathrm{~K}$.
\end{abstract}

Keywords: Magnetic refrigeration, Active magnetic regeneration, Regenerator geometry, Heat transfer, Tapering of regenerator.

\section{Nomenclature}


Acronyms

AMR active magnetic regenerator

COP coefficient of performance

LFMSH $\quad \mathrm{La}(\mathrm{Fe}, \mathrm{Si}, \mathrm{Mn})_{13} \mathrm{H}_{\mathrm{y}}$

MCM magnetocaloric material

Symbols

a minimum distance between the beds in an AMR, [m]

$A_{\mathrm{c}} \quad$ regenerator cross sectional area $\left[\mathrm{m}^{2}\right]$

$a_{s} \quad$ specific area $\left[\mathrm{m}^{-1}\right]$

$B \quad$ regenerator width $[\mathrm{m}]$

c specific heat $\left[\mathrm{J} \mathrm{kg}^{-1} \mathrm{~K}^{-1}\right]$

$d_{\mathrm{h}} \quad$ hydraulic diameter $[\mathrm{m}]$

$\Delta S_{\text {mag }} \quad$ isothermal entropy change $\left[\mathrm{J} \mathrm{kg}^{-1} \mathrm{~K}^{-1}\right]$

$\Delta T_{\text {span }} \quad$ temperature span, $\mathrm{T}_{\text {hot }} \mathrm{T}_{\text {cold }}[\mathrm{K}]$

$h \quad$ regenerator height $[\mathrm{m}]$

$H \quad$ magnetic field $\left[\mathrm{A} \mathrm{m}^{-1}\right]$

$k \quad$ thermal conductivity $\left[\mathrm{W} \mathrm{m}^{-1} \mathrm{~K}^{-1}\right]$

$k_{\text {disp }} \quad$ thermal conductivity of the fluid due to axial dispersion [ $\mathrm{W} \mathrm{m}^{-1} \mathrm{~K}^{-1}$ ]

$k_{\text {stat }} \quad$ static thermal conductivity $\left[\mathrm{W} \mathrm{m}^{-1} \mathrm{~K}^{-1}\right]$

$L \quad$ regenerator length, $[\mathrm{m}]$

$\dot{m} \quad$ mass flow rate $\left[\mathrm{kg} \mathrm{s}^{-1}\right]$

$N \quad$ number of regenerators [-]

$\mathrm{Nu} \quad$ Nusselt number [-]

$P \quad$ pressure $[\mathrm{Pa}]$

$Q_{\mathrm{C}} \quad$ cooling power [W]

$Q_{\mathrm{H}} \quad$ heating power [W]

$Q_{\mathrm{H}} \max \quad$ maximum heating power [W]

$R_{i} \quad$ internal radius of the regenerators, [mm]

$s \quad$ specific entropy $\left[\mathrm{J} \mathrm{m}^{-3} \mathrm{~K}^{-1}\right]$

$t \quad$ time $[\mathrm{s}]$

$T \quad$ temperature $[\mathrm{K}]$

$T_{\mathrm{C}} \quad$ Curie temperature [K]

$T_{\text {cold }} \quad$ cold end temperature [K]

$T_{\text {hot }} \quad$ hot end temperature [K]

$T_{w} \quad$ AMR working temperature $[\mathrm{K}]$

$W \quad$ total work [W] 
axial position [m]

Greek Symbols

$\begin{array}{ll}\alpha & \text { tapering angle, }\left[{ }^{0}\right] \\ \Delta & \text { increment } \\ \varepsilon & \text { porosity [-] } \\ \rho & \text { density }\left[\mathrm{kg} \mathrm{m}^{-3}\right]\end{array}$

Subscripts

i initial state index

f fluid index

fin final state index

r solid refrigerant index

\section{INTRODUCTION}

In recent years, magnetocaloric refrigeration devices working at room temperature reached significant performance due to improvements of the material properties, material shaping, the possibility of using more efficient and stronger magnets, and flow optimization into the regenerators (Jacobs et al., 2014).

A typical active magnetic regenerator (AMR) cycle starts from the adiabatic magnetization process, which causes the increase of the magnetocaloric material (MCM) temperature. At the same time, the hot blow occurs, with the heat transfer fluid flowing through the porous bed from the cold to the hot end and being heated by the MCM. Afterwards, the fluid rejects the excess heat to the ambient, at the hot end. In the next step the regenerator is adiabatically demagnetized, causing a temperature decrease of the MCM, and the hotto-cold flow will reject heat to the solid and reach a lower temperature than the initial condition. Finally, the fluid absorbs heat, i.e. a cooling load, at the cold end. After several cycles, a temperature gradient is established into the regenerator along the flow direction, and a periodical steady state is achieved. The net enthalpy flows at the ends are the heating and cooling power, $Q_{\mathrm{H}}$ and $Q_{\mathrm{C}}$, respectively.

The material's choice and performance have a significant effect on the cooling and heating power and the regenerator efficiency. Therefore, the simulation of the performance of a layered regenerator to predict the cooling or heating capacity and the efficiency of an active magnetic regenerator is a crucial step in the design of high efficiency device (Aprea et al., 2011).

Regarding the MCM, up to now, mostly of the magnetocaloric devices have used materials with a second order phase transition. These materials show a smooth entropy change across a broad temperature range, when the transition between the ferromagnetic and the paramagnetic phase takes place. To improve the AMR performance, researchers presented various interesting materials with compelling magnetocaloric properties. Among them, the magnetocaloric materials with a first-order phase transition at the Curie temperature have a large isothermal entropy change $\Delta S_{\mathrm{mag}}$, as shown in (Basso et al., 2015). The $\Delta S_{\mathrm{mag}}$ is defined as

$$
\Delta S_{\text {mag }}\left(T, H_{i}: H_{f i n}\right) \equiv S\left(T, H_{f i n}\right)-S\left(T, H_{i}\right)
$$

with $H$ and $T$ denoting magnetic field and temperature, respectively, and the subscripts $i$ and fin indicating initial and final state, respectively. 
The peak of $\Delta S_{\mathrm{mag}}$ of the first order material is generally larger compared to MCMs with a pure second order transition, like gadolinium (Gd). In particular, the first order material considered in this paper, $\mathrm{La}(\mathrm{Fe}, \mathrm{Mn}, \mathrm{Si})_{13} \mathrm{H}_{\mathrm{y}}$, is an attractive first order material and is subject to extensive research due to the high values of $\Delta S_{\mathrm{mag}}$, the small hysteresis effect, adjustable $T_{\mathrm{C}}$, relatively high thermal conductivity, and high stability (Fujieda et al., 2004), (Morrison et al., 2012).

This particular first order material was developed starting from $\mathrm{La}\left(\mathrm{Fe}_{x} \mathrm{Si}_{1-\mathrm{x}}\right)_{13}$, where the Curie temperature can be tuned by the addition of hydrogen (Fujita et al., 2003). As Barcza et al. (Barcza et al., 2011) pointed out in their work it is difficult to control partial hydrogenation on the industrial level with high accuracy. The addition of Mn reduced the Curie temperature, allowing a full hydrogenation of the samples.

Wang et al. (Wang et al., 2011) investigated the effect of hydrogenating process on the homogeneity of hydrogen absorption in the La-Fe-Mn compounds. They pointed out that the distribution of hydrogen atoms in the compounds becomes more uniform with increasing hydrogen pressure and annealing temperature. They also obtained homogeneous hydrides of $\mathrm{La}_{0.8} \mathrm{Ce}_{0.2}\left(\mathrm{Fe}_{0.985} \mathrm{Mn}_{0.015}\right)_{11.5} \mathrm{Si}_{1.5}$, and they showed how the Curie temperatures $\left(T_{\mathrm{C}}\right)$ of the hydrides of the compounds can be adjusted in the room temperature range from 279 to $312 \mathrm{~K}$, with changes of Mn content.

Although large $\Delta S_{\mathrm{mag}}$ generally means higher performance, it decreases quickly if the material is working at temperatures far from their $T_{\mathrm{C}}$. The main reason for this inconvenient behavior of the first order materials is the very narrow peak of $\Delta S_{\text {mag }}$ that characterizes this group of materials. As already proven by some experimental results, multi-layer regenerators, in which each layer is aligned to make sure the $T_{C}$ of each material follows the temperature gradient, can be a solution to this issue (Jacobs et al., 2014). Larger temperature spans as well as cooling capacities are expected in multi-layer regenerators using first order materials compared to single-material regenerators. Smith et al. (Smith et al., 2012) pointed out that for first order materials, the peak in the specific heat will move significantly with the applied field, and in reality the $\Delta S_{\text {mag }}$ peaks also show a similar shift to higher temperature in a high applied field (Morrison et al., 2012). It is implied that the best working temperature for the first order material is expected to be slightly higher than the Curie temperature (Lei et al., 2015).

In AMR devices, not only the magnetocaloric properties of materials, but also the regenerator geometry plays a fundamental role in the system performance. Flow distribution into the porous matrix, packing of the MCM into each bed, reduction of the global pressure drop and positioning in the AMR device make further optimization of the geometry possible but challenging (Tušek et al., 2013), (Lei et al., 2014). Although in literature the devices with the best heating and cooling power have the regenerators placed circumferentially on a plane (Russek et al., 2010), (Zimm et al., 2006), the effect of having a tapered regenerator was never studied. We can define a tapered regenerator as a regenerator where the two lateral walls are inclined at a certain angle to the fluid flow direction, resulting in a shape with a wider cross sectional area at one of its two ends, and a smaller at the other end.

Certainly, apart from the thermodynamic point of view, the use of tapering regenerators improves the efficiency of utilization of the airgap (as shown in Fig. 1), allowing to design (with a fixed amount of MCM) more compact prototypes, with an immediate reduction of the size and, consequently of the costs, of the magnet. In this paper, the performance of an AMR with tapered regenerator beds is presented as a function of the tapering angle and of the hot side temperature, which varies from $307 \mathrm{~K}$ to $315 \mathrm{~K}$, with a constant temperature span $\left(\Delta T_{\text {span }}\right)$ of $25 \mathrm{~K}$. As we will show in this paper, multi-layer regenerators using first order materials are very sensitive to the working temperature $\left(T_{w}\right)$, and a study of how the performance of a regenerator bed changes according to the $T_{w}$ and the tapering angle is presented here.

\section{THE GEOMETRICAL ADVANTAGE OF TAPERING}

In AMR devices, the magnet is the most expensive component. For this reason, it is very important to design a more compact system, in order to minimize the costs of the entire machine.

Considering the design of a high efficiency AMR, in order to better exploit the volume of the airgap, a circumferential distribution of the regenerators is desired. It is possible to quantify the volumetric advantage given by the tapering of such an arrangement by fixing several geometrical parameters like the number of regenerators $N$, the minimum distance $a$ between the beds, the internal radius of the regenerators $R_{\mathrm{i}}=N$. $(B+a)$, and the total MCM volume $N \cdot L \cdot B \cdot h$ of the parallel walls regenerators, as shown in Fig. 1 and Fig. 2. The distance $a$ has a lower limit due to the space occupied by the housing of the regenerators, and is needed 
to avoid magnetic field interactions effects that could decrease the performance of the AMR. By making the AMR more compact, i.e. by decreasing $a$, we achieve a better squeezing of the tapered regenerators with respect to the straight ones, with a more uniform utilization of the airgap.

In particular, by fixing the geometrical constraint of the regenerators, the advantage can be quantified as an increase of the MCM volume of

$$
N \cdot h \cdot L^{2} \cdot \tan (\alpha)
$$

using regenerator beds with a tapering angle of $\alpha$.

The calculation of this gain in MCM volume will be presented in the results, specifically for the regenerator geometry of our device.

\section{THE 1D SIMULATION MODEL}

The well-known 1D model developed by Engelbrecht (Engelbrecht et al., 2013) was adapted to simulate the heating and cooling power and the coefficient of performance (COP) of a tapered regenerator working in an AMR. The latest update of the model is the one described in (Lei et al., 2015), and it was adapted to simulate tapered bed regenerators keeping a constant length of the layers along the regenerators. Considering heat transfer via conduction and convection in a regenerator bed, and assuming that there are no energy exchanges with the environment, the partial differential equations of the heat transfer fluid and magnetocaloric material in the transient model can be written as

$$
\begin{gathered}
\frac{\partial}{\partial x}\left(k_{\text {disp }} \frac{\partial T_{f}}{\partial x}\right) A_{c}-\dot{m}_{f} c_{f} \frac{\partial T_{f}}{\partial x}-\frac{N u k_{f}}{d_{h}} a_{s} A_{c}\left(T_{f}-T_{r}\right)+\left|\frac{\partial P}{\partial x} \frac{\dot{m}_{f}}{\rho_{f}}\right|=\rho_{f} A_{c} \varepsilon c_{f} \frac{\partial T_{f}}{\partial t} \\
\frac{\partial}{\partial x}\left(k_{\text {stat }} \frac{\partial T_{r}}{\partial x}\right) A_{c}+\frac{N u k_{f}}{d_{h}} a_{s} A_{c}\left(T_{f}-T_{r}\right)+A_{c}(1-\varepsilon) \rho_{r} T_{r}\left(\frac{\partial s_{r}}{\partial H}\right)_{T} \frac{\partial H}{\partial t}= \\
A_{c}(1-\varepsilon) \rho_{r} c_{H} \frac{\partial T_{r}}{\partial t}
\end{gathered}
$$

where $k, \rho, c$, and $s$ are the thermal conductivity, density, specific heat, and specific entropy; $A_{c}, d_{h}, a_{s}$, and $\varepsilon$ are the cross sectional area, hydraulic diameter, specific area, and porosity, which reflect the geometry characteristics of a regenerator; $x, t, \dot{m}$, and $H$ are the axial position, time, mass flow rate, and internal magnetic field. The subscripts $f$ and $r$ represent fluid and solid refrigerant, respectively. The thermal conductivity due to fluid dispersion is $k_{\text {disp, }}$, static thermal conductivity is $k_{\text {stat }}$, and the pressure drop is $\partial P / \partial x$. From left to right, the terms in Eq. (3) are axial conduction, enthalpy flow, heat transfer, viscous dissipation and energy storage on the fluid side separately. For solid governing equation, i.e., Eq. (4), the terms are axial conduction, heat transfer, magnetic work and energy storage, respectively. The fluid and solid domains are coupled through the convective heat transfer term. In each AMR cycle, the fluid is assumed to enter the packed bed with a constant temperature $T_{\text {hot }}$ at the hot end during the hot-to-cold blow, and $T_{\text {cold }}$ at the cold end during the cold-to-hot blow, synchronized with a periodically varying magnetic field. These reservoir temperatures are assumed to be equal to the indoor and ground temperatures, respectively, since the heat exchangers are not accounted for in these simulations. The temperature span is $\Delta T_{\text {span }}=T_{\text {hot }}-T_{\text {cold. }}$. The model solves for periodic steady state of the AMR and then calculates the heating power from the resulting temperature and fluid flow profiles. 
Considering the performance of a heat pump, the following equation is used for the evaluation of the COP:

$$
C O P=\frac{Q_{H}}{W}=\frac{Q_{H}}{Q_{H}-Q_{C}}
$$

where $W$ is the total work input to the system.

For the simulations, the geometrical characteristics of the regenerator of the machine planned and designed for the ENOVHEAT project were used as parameters, as well as the applied field and the flow distribution, in order to get results as useful as possible for the design of the machine itself.

In the model, the heat transfer fluid flows through 13 regenerator beds periodically, and the flow is synchronized with the changing magnetic field. The heat transfer fluid is water mixed with $20 \%$ ethylene glycol by volume, while the regenerator material is $\mathrm{La}(\mathrm{Fe}, \mathrm{Si}, \mathrm{Mn})_{13} \mathrm{H}_{\mathrm{y}}(\mathrm{LFMSH})$ (Barcza et al., 2011). We obtained the temperature-entropy curve of this material experimentally for several working temperatures and for several values of $T_{\mathrm{C}}$, as explained in Lei et al. (Lei et al., 2015), and derived the values for other $T_{\mathrm{C}} \mathrm{s}$ by shifting the curve to a higher or lower value of $T_{\mathrm{C}}$. One of the characteristics of the first order materials is that they have a large $\Delta S_{\text {mag }}$, which generally improves the performance of the AMR when operating at its design point, but the values decrease rapidly at temperatures away from its $T_{C}$. This characteristic is related to the sharp peak in the entropy curve, and as a consequence first order material are not able to work optimally over a broad temperature region, but only close to the values where the peak of $\Delta S_{\text {mag }}$ appears. Moreover, because for first order materials the peak in the specific heat and consequently in the $\Delta S_{\text {mag }}$ will move significantly to higher temperatures by increasing the applied field, it is expected that the best working temperature for the regenerator is higher than the Curie temperature of the layer with the highest $T_{\mathrm{C}}$ (Smith et al., 2012). Therefore, to show the effect of this sharp peak of the $\Delta S_{\mathrm{mag}}$ on the AMR performance, we studied the behavior of the regenerator keeping the $\Delta T_{\mathrm{span}}$ constant, but shifting the working temperatures.

In this work, each regenerator bed has a length of $59 \mathrm{~mm}$ and an average cross sectional area of $1043 \mathrm{~mm}^{2}$, measured in the middle of the regenerator, as it is shown in the Fig. 3. The height of the regenerator is constant. Geometrically, the middle section is held fixed, while the sides of the regenerator are scaled by the desired angle. The angles considered in the simulations are in the range $-40^{\circ}$ and $40^{\circ}$, but according to the results, the most interesting range for an optimized application is represented by the angles $-20^{\circ}$ to $20^{\circ}$. The reason for this statement is that, as shown in Fig. 4 and Fig. 5, a tapering angle bigger than $20^{\circ}$, independently on the direction of the tapering, will result in a sensible decrease of the performance of the AMR. It is important to notice that the difference between positive and negative tapering angle is not geometrical, but related to the distribution of the different $T_{C}$ of the MCM along the regenerator. This distribution defines the hot and the cold side of the regenerator. A negative tapering means that the MCM with the lowest $T_{C}$ is placed in the wider cross section side of the regenerator. The opposite occurs in the case of positive tapering.

The working frequency is $2 \mathrm{~Hz}$ for all model cases. The complete list of the main modelling parameters is presented in Table 1.

\section{SIMULATION METHODOLOGY}

In this paper, several 1D simulations were run in order to investigate two different aspects: the effect of the tapering and of the shifting of the ambient condition $\left(T_{\text {hot }}\right)$ on the performance of the AMR. 
The investigation of the impact of the tapering angle of a regenerator on the AMR performance is a very interesting and relevant topic, because in literature the AMRs that show the best performance have the regenerators placed circumferentially on a plane.

As already stated, the materials are predicted to perform better when the working temperatures are higher than the Curie temperatures.

In our case we fixed the number of layers to 10 . The main reason is that 10 layers are an upper limit to allow a good precision in the assembly of the entire MCM block, permitting to have a $\Delta T_{\text {span }}$ of around $25 \mathrm{~K}$. Fixing the number of layers, the length of each layer is also fixed at $5.9 \mathrm{~mm}$. For this reason, each material will have the same length in the flow direction but different mass, because of the variation of the cross section area along the regenerator. The Curie temperatures of the layers are, starting from the cold end: 284 $\mathrm{K}, 286.5 \mathrm{~K}, 289 \mathrm{~K}, 291.5 \mathrm{~K}, 294 \mathrm{~K}, 296.5 \mathrm{~K}, 299 \mathrm{~K}, 301.5 \mathrm{~K}, 304 \mathrm{~K}, 306.5 \mathrm{~K}$, while the $\Delta T_{\text {span }}$ is fixed at 25 $\mathrm{K}$. A total amount of $2.4 \mathrm{~kg}$ of MCM is considered, and the target performance is expected to be for a flow rate around $2000 \mathrm{~L} \mathrm{~h}^{-1}$. The porosity of the MCM can be assumed to be 0.5 with an average sphere diameter of $200 \mu \mathrm{m}$.

During the first group of simulations, i.e. the ones that aim to show the sensitivity of the performance of the AMR to the working temperature, $T_{\text {hot }}$ and $T_{\text {cold }}$ are shifted at the same time by -2 to $6 \mathrm{~K}$.

In the second group of simulations, $\Delta T_{\text {span }}$ and $T_{\text {hot }}$ were kept constant, and the resulting AMR performance has been affected by the tapering angle of the regenerator beds only.

\section{RESULTS AND DISCUSSION}

In this section, the results of the two groups of simulations mentioned before will be presented and discussed. To understand in more detail the complex interactions between the variation of both the tapering angle and of $T_{\mathrm{w}}$, the maximum value of the heating power as a function of $T_{\text {hot }}$ is reported for each angle in Fig. 6, regardless of the flow rate.

By considering a global view of the results of the simulations, it is straightaway evident how large the influence of $T_{\mathrm{w}}$ on the performance of an AMR is. Trying to quantify the effect of $T_{\mathrm{w}}$, we can say that for every $1 \mathrm{~K}$ of variation of the $T_{\mathrm{w}}$ far from the optimum value $310 \mathrm{~K}$, the loss of performance is about $150 \mathrm{~W}$ $\mathrm{K}^{-1}$, in average. This quantity represents a big limit for the use of first order material in an AMR, because despite their higher absolute performance compared to second order materials, they do not allow a machine to work out of the design conditions at high efficiency. The specific behavior described above is clearly visible in Fig. 6. From the figure, we can see that the straight channel is the most steady in performance, while the curves representing the best performance for the other angles are quite symmetrical with respect to the $T_{\text {hot }}$ of $310 \mathrm{~K}$. Considering still Fig. 6, an interesting observation is that it is ideally possible to compensate the decreasing of the performance of an AMR due to the variation of the $T_{\mathrm{w}}$, by varying the tapering angle of the regenerator bed. For higher values of $T_{\text {hot }}$, positive tapering is needed to maintain high performance, while negative tapering gives better performance for lower $T_{\text {hot }}$. We can notice how sensitive the performance of a regenerator filled with first order MCM is to every small variation of the $T_{\mathrm{W}}$, and this makes such regenerators very specific for their working conditions.

We now focus our attention on the best absolute performance, and consider the $T_{\mathrm{w}}$ as fixed. As could be expected from the choice of the $T_{\mathrm{C}} S$, the best performance of heating and cooling power is for $T_{\mathrm{w}}: 285 \rightarrow 310$ $\mathrm{K}$, in a slightly higher temperature range with respect to the $T_{C}$ distribution, and the curves related to this temperature range are reported in Fig. 4 and Fig. 5. The results for the case of $T_{\mathrm{w}}: 286 \rightarrow 311 \mathrm{~K}$ are very similar to the previous.

Considering the COP, the effect of the tapering is more evident and more interesting. If we focus on the case with the best performance, i.e. for $T_{\mathrm{w}}: 285 \rightarrow 310 \mathrm{~K}$, the values of the COP for the tapering range $-20^{\circ}$ to $20^{\circ}$ 
are reported in Fig. 7. We can see that the best results are obtained for negative angles, and this behavior can be explained considering the pressure loss of the fluid flow along the regenerator. The cases with negative tapering angle have a slightly lower pressure loss with respect to the $0^{\circ}$ or positive tapering angle cases. One possible explanation for this is that a negative angle means that the cold side of the regenerator has a wider cross section compared to the straight bed. With such geometry, the stream at the cold side, that is also the one with the highest viscosity, finds less resistance in flowing through the channel, and for this reason there is a reduction in pressure drop and an improvement in the efficiency of the system.

As can be seen by the complete view shown in Fig. 8, the behavior of the pressure loss as a function of tapering angle confirms this theory. In the graph, the pressure losses as a function of the tapering angle are reported, considering all the most interesting flow rates for the real prototype, i.e. in a range from around 80 $\mathrm{L} \mathrm{h}^{-1}$ up to $2900 \mathrm{~L} \mathrm{~h}^{-1}$.

Fig. 8 also illustrates that a regenerator with a tapering angle of $-10^{\circ}$ shows a slight minimum in pressure loss with respect to other angles. Anyway, it seems that there are not large variations of the pressure loss in the tapering range $-20^{\circ}$ to $+10^{\circ}$, confirming that a negative tapering angle is usually a better choice, at least from the pressure side. The minimum in the pressure loss becomes more evident with the increasing of the flow rate, being the pressure loss proportional to the square of the flow rate itself.

Finally, considering the possibility to have better air-gap utilization with the tapered regenerator bed, the advantage is quantified in Table 2 for the specific case of our device. The gain in MCM volume is shown in the right column as a function of the tapering angles reported in the left column. The values presented in Table 2 are obtained by applying Eq. (2) to our particular device, with the regenerator beds positioned circumferentially at a radius of $0.2 \mathrm{~m}, \mathrm{a}=0.051 \mathrm{~m}, \mathrm{~h}=0.017 \mathrm{~m}$, . All the geometrical quantities are reported in Table 1. We can notice how the MCM increases significantly for every small variation of the tapering angle.

For our specific device, we fixed a tapering angle of $-10^{\circ}$, achieving an increase in the air-gap utilization of the $22 \%$ with respect to the straight regenerator bed.

\section{CONCLUSIONS}

Tapered 10-layer regenerators filled with the first order material LFMSH were investigated to show the impact of the tapering angle on the heating and cooling power of an AMR. In particular, 1D simulations were run to optimize the shape of the regenerator of the AMR designed within the Danish project ENOVHEAT. In general, tapering a regenerator increases the specific cooling power (per unit volume) of the device, and allows a more efficient use of the air-gap, being analogous to increasing the volume of MCM in the same magnetized volume. Therefore, in a radial distribution of regenerators, tapering gives a significant volume optimization advantage compared to the parallel wall configuration. As main consequence, the prototype can be more compact, reducing in particular the volume of the magnet, which is the most expensive component of an AMR.

A 10-layer regenerator AMR exhibits the best performance at a $T_{\mathrm{w}}$ slightly higher than the $T_{\mathrm{C}}$ range of the layers. This is an important indication to keep in mind during the design of an AMR, and in particular for the choice of the $T_{C} \mathrm{~S}$ of the MCM according to the desired $T_{\mathrm{w}}$ of the AMR.

No significant absolute improvement of the heating and cooling power of an AMR can be achieved with the tapering of the regenerators, but the device becomes slightly more efficient with a bed tapered such that the cold end has a larger cross section than the hot end, as it is shown by the pressure loss curve (Fig. 8) and from the COP (Fig. 7).

Considering the pressure loss along the regenerator plotted in Fig. 8, we can state that for most of the tapering angles the gain obtained from viscosity is less than the loss in geometry.

Tapering represents a small disadvantage for performance, except for a small range of negative angles where the system can get an improvement in efficiency. This improvement in performance comes mainly as a help from viscosity, because while increasing the cross section of the cold side of the regenerator we can reduce the loss of the more viscous fluid. In most of the cases, the performance of the AMR begins to decrease significantly for a large value of the tapering angles, i.e. $25^{\circ}$. 
Considering the results of the 1D simulations of the AMR, a tapering angle of $-10^{\circ}$ seems to be the best compromise to design a realistic device having the regenerators circumferentially distributed over a disc, and to have a benefit in the COP given by the slight minimum in pressure loss. According to Figure 1 and Table 1 this will also result in the possibility of increasing the amount of MCM in the regenerator by $22 \%$. These considerations, together with the geometrical constrains of our prototype, led us to choose a tapering angle of $-10^{\circ}$ for the 13 regenerators.

\section{ACKNOWLEDGMENTS}

This work was financed by the ENOVHEAT project, which is funded by the Innovation Fund Denmark (contract no 12-132673).

\section{REFERENCES}

Aprea, C., Greco, A., Maiorino, A., 2011. A numerical analysis of an active magnetic regenerative refrigerant system with a multi-layer regenerator. Energy Convers. Manag. 52, 97-107. doi:10.1016/j.enconman.2010.06.048

Barcza, A., Katter, M., Zellmann, V., Russek, S., Jacobs, S., Zimm, C., 2011. Stability and Magnetocaloric Properties of Sintered $\mathrm{La}(\mathrm{Fe}, \mathrm{Mn}, \quad \mathrm{Si})_{13} \mathrm{H}_{\mathrm{z}}$ Alloys. IEEE Trans. Magn. 47, 3391-3394. doi:10.1109/TMAG.2011.2147774

Basso, V., Küpferling, M., Curcio, C., Bennati, C., Barzca, A., Katter, M., Lovell, E., Turcaud, J., Cohen, L.F., Curcio, C., Bennati, C., Basso, V., Michaela, K., Cohen, L.F., 2015. Specific heat and entropy change at the first order phase transition of La ( Fe-Mn-Si ) ${ }_{13}-\mathrm{H}$ compounds 53907. J. Appl. Phys. 118, 053907. doi:10.1063/1.4928086

Engelbrecht, K., Nielsen, K.K., Bahl, C.R.H., Carroll, C.P., van Asten, D., 2013. Material properties and modeling characteristics for $\mathrm{Mn} \mathrm{Fe} \mathrm{P}_{1-\mathrm{x}} \mathrm{As}_{\mathrm{x}}$ materials for application in magnetic refrigeration. $\mathrm{J}$. Appl. Phys. 113, 173510. doi:10.1063/1.4803495

Fujieda, S., Hasegawa, Y., Fujita, A., Fukamichi, K., 2004. Thermal transport properties of magnetic refrigerants $\mathrm{La}\left(\mathrm{Fe}_{\mathrm{x}} \mathrm{Si}_{1-\mathrm{x}}\right)_{13}$ and their hydrides, and Gd 5 Si 2 Ge 2 and MnAs. J. Appl. Phys. 95, 2429-2431. doi:Doi 10.1063/1.1643774

Fujita, A., Fujieda, S., Hasegawa, Y., Fukamichi, K., 2003. Itinerant-electron metamagnetic transition and large magnetocaloric effects in $\mathrm{La}\left(\mathrm{Fe}_{\mathrm{x}} \mathrm{Si}_{1-\mathrm{x}}\right)_{13}$ compounds and their hydrides. Phys. Rev. B 67, 104416. doi:10.1103/PhysRevB.67.104416

Jacobs, S., Auringer, J., Boeder, A., Chell, J., Komorowski, L., Leonard, J., Russek, S., Zimm, C., 2014. The performance of a large-scale rotary magnetic refrigerator. Int. J. Refrig. 37, 84-91. doi:10.1016/j.ijrefrig.2013.09.025

Kirstein, K., Lei, T., Engelbrecht, K., Nielsen, K., Veje, C., Tušek, J., Bahl, C., n.d. Modelling and comparison studies of packed screen regenerators for active magnetocaloric refrigeration.

Lei, T., Nielsen, K.K., Engelbrecht, K., Bahl, C.R.H., Neves Bez, H., Veje, C.T., 2015. Sensitivity study of multi-layer active magnetic regenerators using first order magnetocaloric material $\mathrm{La}(\mathrm{Fe}, \mathrm{Mn}, \mathrm{Si}){ }_{13} \mathrm{H}_{\mathrm{y}} . \mathrm{J}$. Appl. Phys. 118, 14903. doi:10.1063/1.4923356

Morrison, K., Sandeman, K.G., Cohen, L.F., Sasso, C.P., Basso, V., Barcza, A., Katter, M., Moore, J.D., Skokov, K.P., Gutfleisch, O., 2012. Evaluation of the reliability of the measurement of key magnetocaloric properties: A round robin study of $\mathrm{La}(\mathrm{Fe}, \mathrm{Si}, \mathrm{Mn}) \mathrm{H}_{\delta}$ conducted by the SSEEC consortium of European laboratories. Int. J. Refrig. 35, 1528-1536. doi:10.1016/j.ijrefrig.2012.04.001

Russek, S., Auringer, J., Boeder, a, Chell, J., Jacobs, S., Zimm, C., 2010. The performance of a rotary magnet magnetic refrigerator with layered beds. Proceedings of 4th International Conference on Magnetic Refrigeration at Room Temperature, pp. 339-349. 
Smith, A., Bahl, C.R.H., Bjork, R., Engelbrecht, K., Nielsen, K.K., Pryds, N., 2012. Materials challenges for high performance magnetocaloric refrigeration devices. Adv. Energy Mater. 2, 1288-1318. doi:10.1002/aenm.201200167

Tušek, J., Kitanovski, A., Poredoš, A., 2013. Geometrical optimization of packed-bed and parallel-plate active magnetic regenerators. Int. J. Refrig. 36, 1456-1464. doi:10.1016/j.ijrefrig.2013.04.001

Wang, C., Long, Y., Ma, T., Fu, B., Ye, R., Chang, Y., Hu, F., Shen, J., 2011. The hydrogen absorption properties and magnetocaloric effect of $\mathrm{La}_{0.8} \mathrm{Ce}_{0.2}\left(\mathrm{Fe}_{1-\mathrm{x}} \mathrm{Mn}_{\mathrm{x}}\right)_{11.5} \mathrm{Si}_{1.5} \mathrm{H}_{\mathrm{y}}$. J. Appl. Phys. 109, 07A910. doi:10.1063/1.3549560

Zimm, C., Boeder, A., Chell, J., Sternberg, A., Fujita, A., Fujieda, S., Fukamichi, K., 2006. Design and performance of a permanent-magnet rotary refrigerator. Int. J. Refrig. 29, 1302-1306. doi:10.1016/j.ijrefrig.2006.07.014

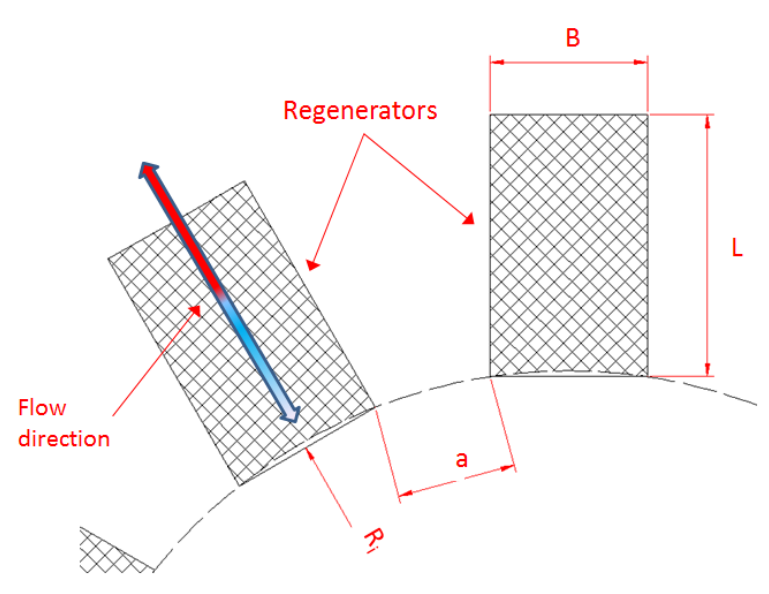

Figure 1. Radial distribution of parallel wall regenerators.

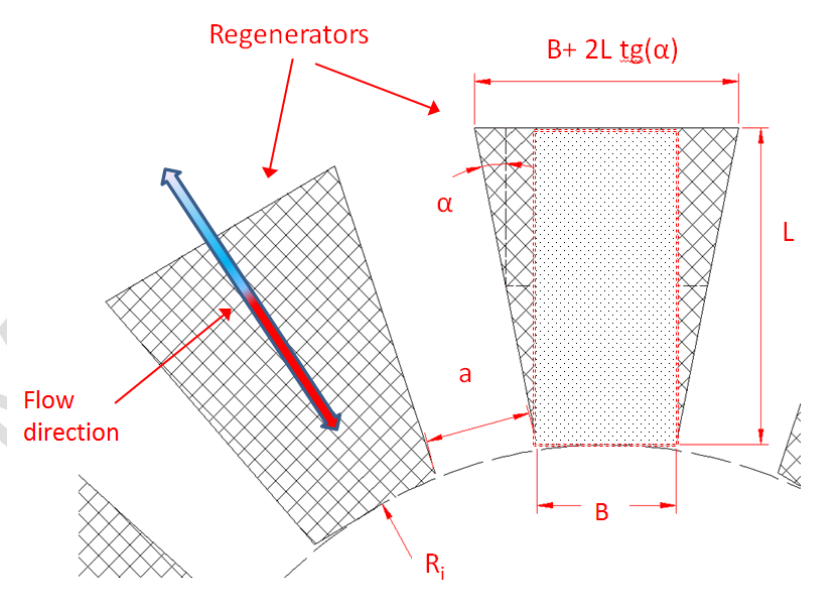

Figure 2. Radial distribution of tapered regenerators.

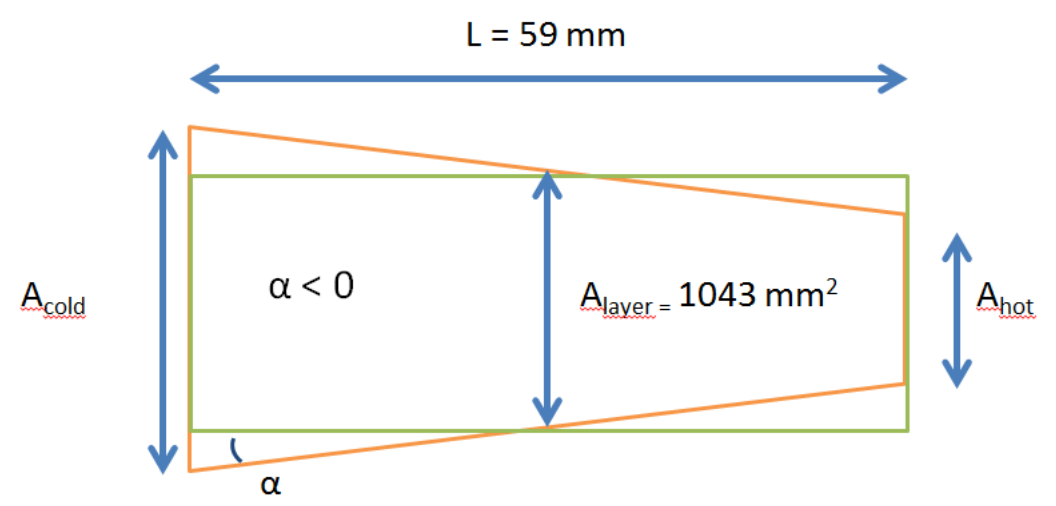

Figure 3. Geometry of the tapered regenerator bed. Boundary of the straight bed in green, while of the tapered bed in orange. 


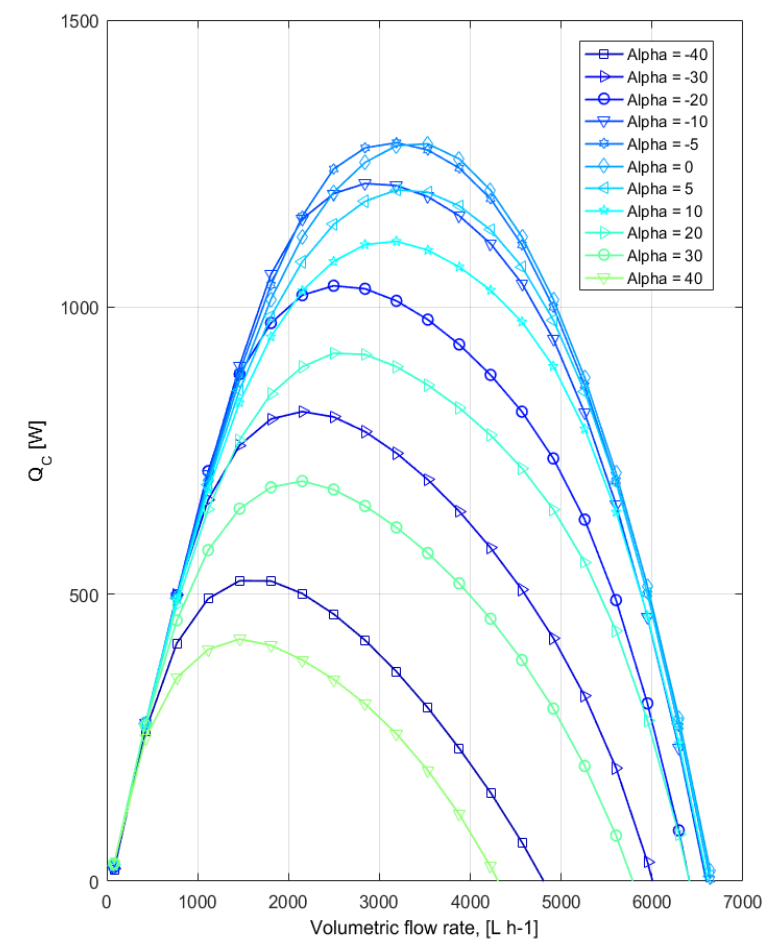

Figure 4. Cooling power curves as a function of the flow rate, $\Delta T_{\text {span }}=25 \mathrm{~K}, \mathrm{~T}_{\mathrm{H}}=310 \mathrm{~K}$. Angle alpha $(\alpha)$ from $-40^{\circ}$ to $40^{\circ}$.

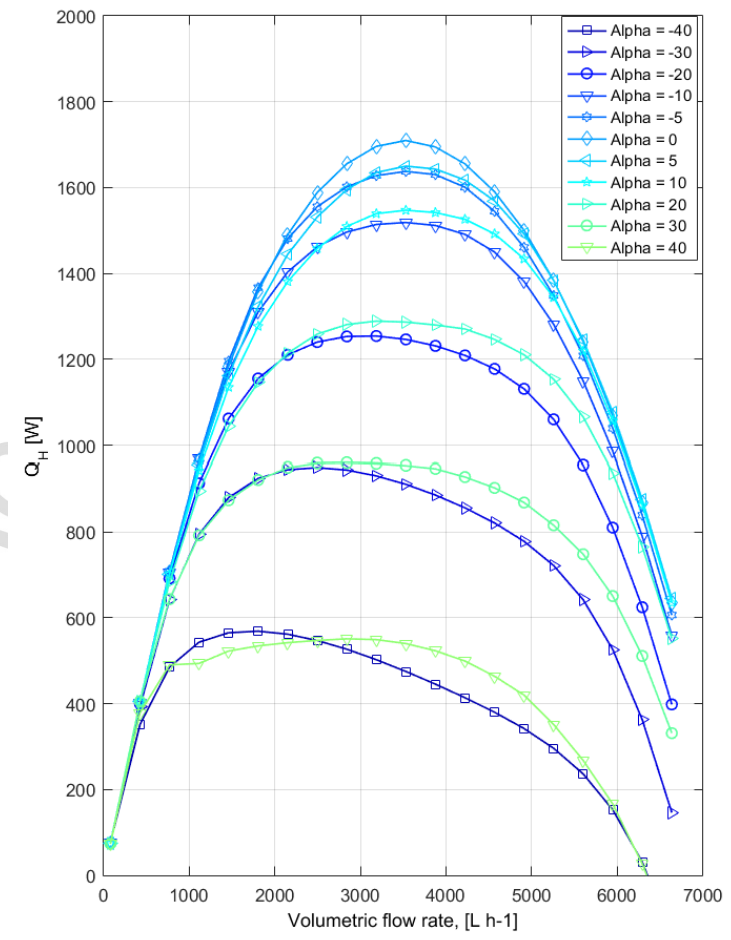

Figure 5 . Heating power curves as a function of the flow rate, $\Delta T_{\mathrm{span}}=25 \mathrm{~K}, \mathrm{~T}_{\mathrm{H}}=310 \mathrm{~K}$. Angle alpha $(\alpha)$ from $-40^{\circ}$ to $40^{\circ}$. 


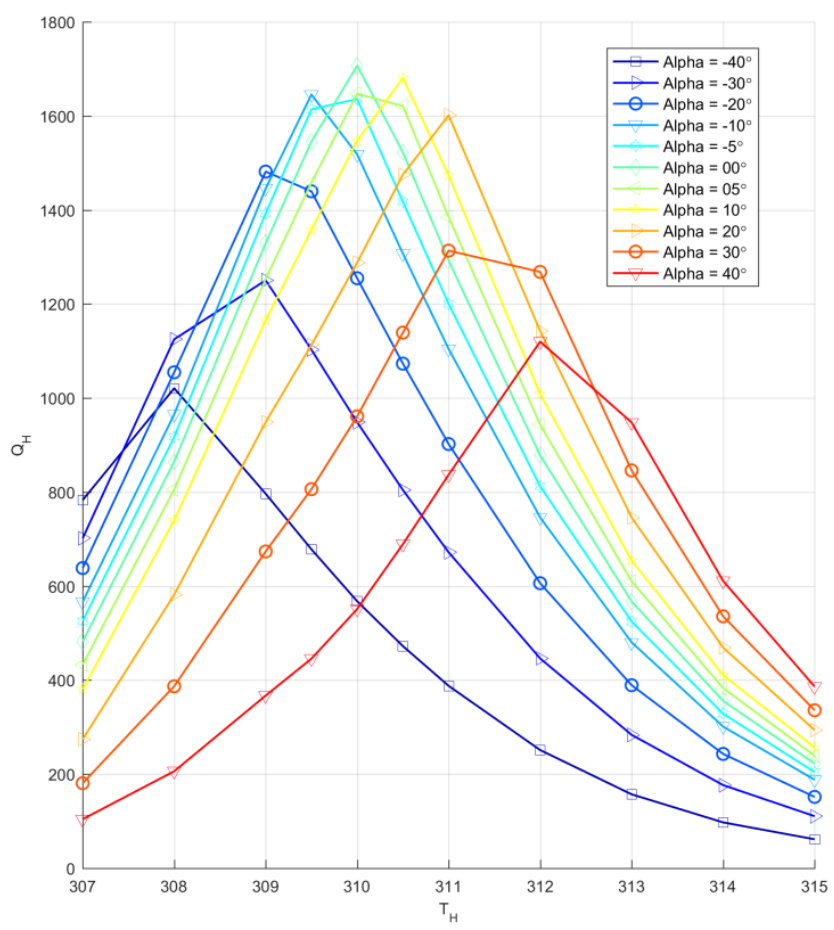

Figure 6. Maximum heating power as a function of $T_{\text {hot }}$, regardless of the flow rate, obtained varying the tapering angle alpha $(\alpha)$ from $-40^{\circ}$ to $40^{\circ}$.

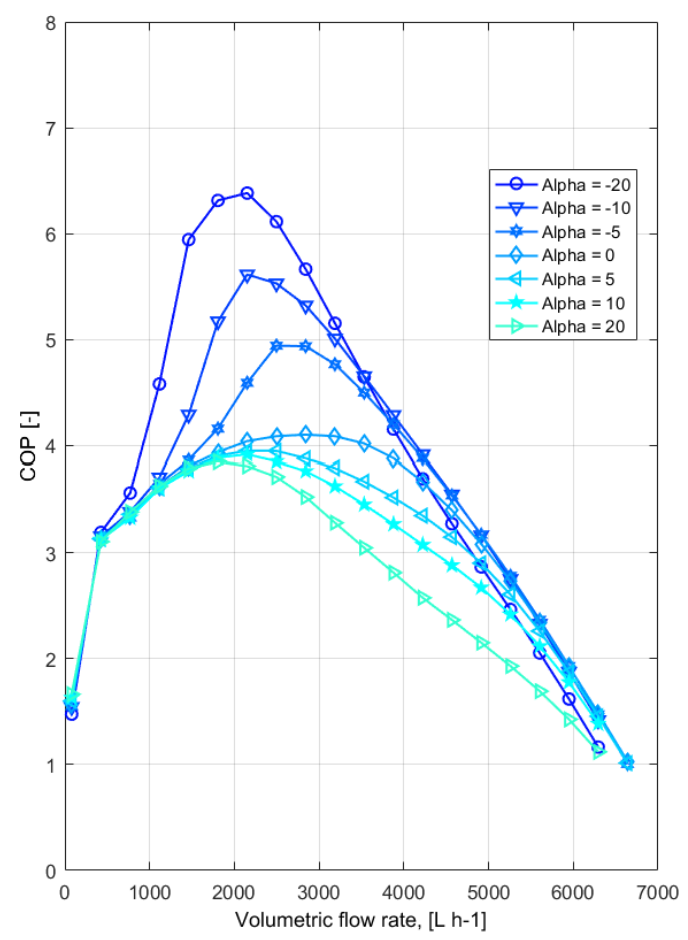

Figure 7. COP as a function of the flow rate, $\Delta T_{\text {span }}=25 \mathrm{~K}, \mathrm{~T}_{\mathrm{H}}=310 \mathrm{~K}$. Angle alpha $(\alpha)$ from $-20^{\circ}$ to $20^{\circ}$. 


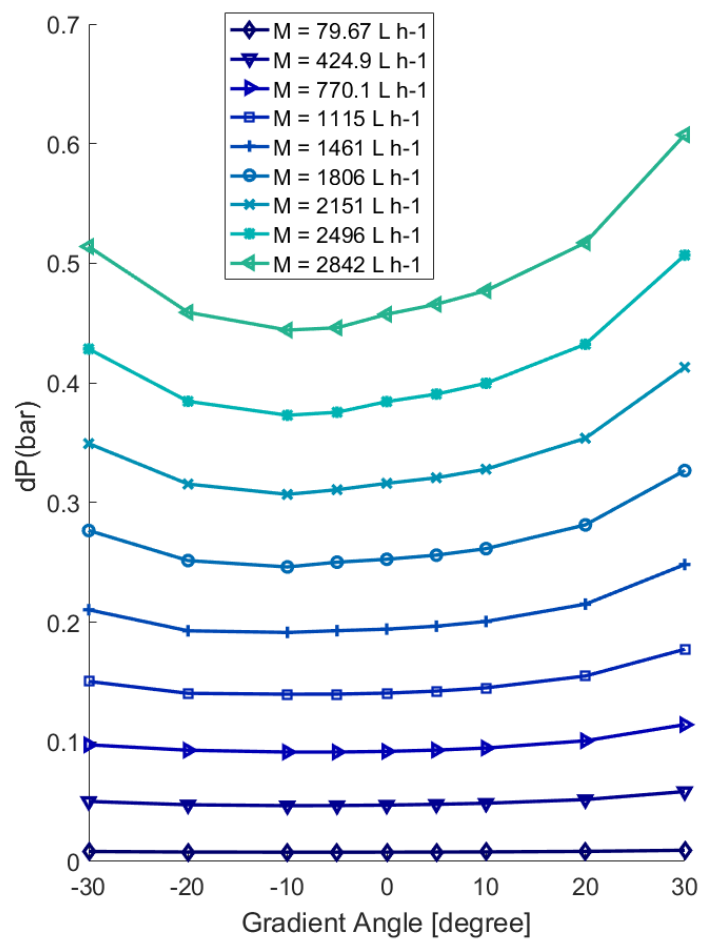

Figure 8. Pressure losses as a function of the gradient angle and the flow rate M. $T_{\mathrm{w}}: 285 \rightarrow 310 \mathrm{~K}$.

Table 1. List of modelling parameters. The results presented in this paper refer to 1D simulation where the following parameters were used.

\begin{tabular}{|c|c|c|}
\hline Parameter & Value & Unit \\
\hline Maximum applied magnetic field & 1.6 (1.4 in average) & $\mathrm{mm}^{2}$ \\
\hline Cross sectional area, $A_{\mathrm{c}}$ & 1043 (measured in the middle of the regenerator) & - \\
\hline Number of MCM layers & 10 & $\mathrm{~m}$ \\
\hline Regenerator length, $L$ & 0.059 & $\mathrm{~m}$ \\
\hline MCM height, $h$ & 0.017 & $\mathrm{~m}$ \\
\hline Regenerator width, $B$ & 0.051 & $\mathrm{~m}$ \\
\hline Regenerator radius, $\mathrm{R}_{\mathrm{i}}$ & 0.2 & $\mathrm{~Hz}$ \\
\hline Frequency & 2 & - \\
\hline Regenerator bed number, $N$ & 13 & - \\
\hline Bed geometry & Packed sphere bed & $\mu \mathrm{m}$ \\
\hline Sphere diameter & 200 & $\mathrm{~kg}$ \\
\hline Porosity & 0.5 & $\mathrm{~h}^{-1}$ \\
\hline FCM mass & 2.4 & \\
\hline
\end{tabular}


Table 2. MCM volume gain for our specific prototype, having fixed the geometry of the regenerator bed and the radius $\mathrm{R}_{\mathrm{i}}$, according to the values reported in Table 1 .

\begin{tabular}{|c|c|}
\hline Angle $\left({ }^{\circ}\right)$ & Volume of MCM ( L ) \\
\hline 0 & 0.66 \\
\hline 5 & $+11 \%$ \\
\hline 10 & $+22 \%$ \\
\hline 15 & $+34 \%$ \\
\hline 20 & $+45 \%$ \\
\hline
\end{tabular}




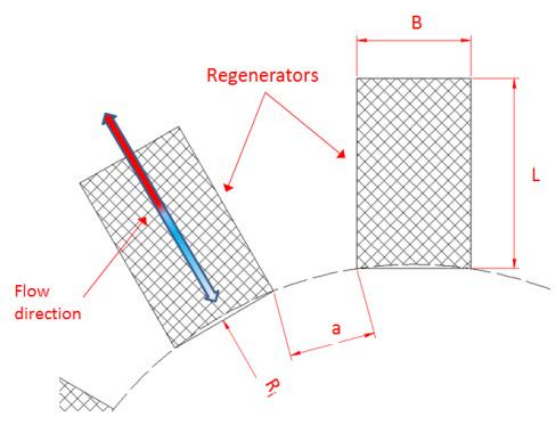

Fig. 1.tiff 


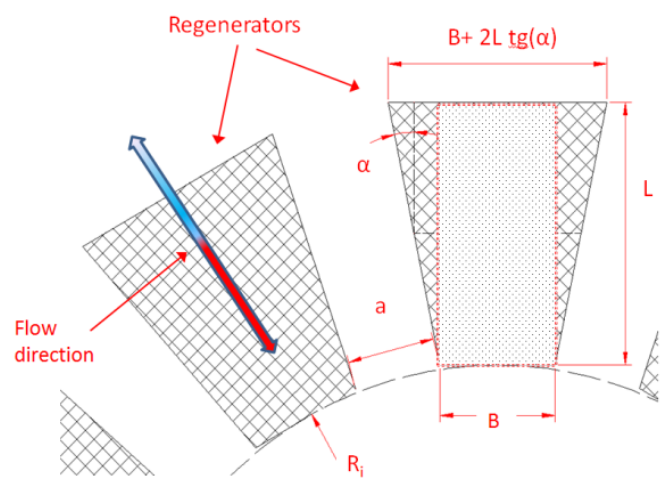

Fig. 2.tiff 


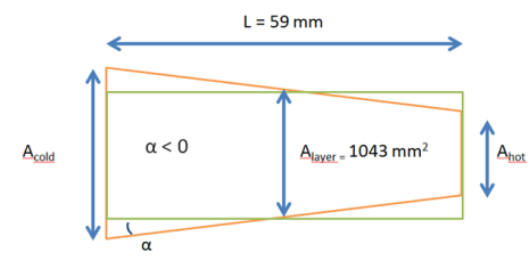

Fig. 3.tiff 